\title{
Calcium and sulphur distribution in fired clay brick in the presence of a black reduction core using micro X-ray fluorescence mapping
}

\author{
L.Gredmaier ${ }^{\mathrm{a}, 1, *}$ C.J.Banks ${ }^{\mathrm{a}, 1}$, R.B. Pearce ${ }^{\mathrm{b}, 1}$ \\ ${ }^{a}$ School of Civil Engineering and the Environment, University of Southampton, Highfield,Southampton SO17 1BJ, UK \\ ${ }^{b}$ National Oceanography Centre, University of Southampton, Waterfront Campus, European Way, Southampton, SO14 3ZH, \\ $U K$
}

\begin{abstract}
A new finding of the observation of an elemental gradient or zoning of calcium and sulphur in fired brick bodies is described, that does not appear to have been reported in the literature before. Many raw clays used in brickmaking and pottery contain sulphur and calcium evenly distributed in low amounts in the unfired clay body. However, when the clay body is fired in the kiln at $1050^{\circ} \mathrm{C}$, the elements sulphur and calcium appear to combine to a compound, most probably calcium sulphate. The formation of calcium sulphate, visualised using energy dispersive imaging micro X-ray fluorescence ( $\mu-\mathrm{XRF})$, only occurs around a so-called reduction core, also known as 'black core', caused by reduced magnetite $\mathrm{Fe}_{3} \mathrm{O}_{4}$ in the centre of the brick body. The presence of a black reduction core appears to cause the formation of a calcium sulphate layer around the black reduction core. This research contributes to the understanding of phenomena like salt formation, efflorescence and durability in solid clay brick bodies. Large sums are spent on building conservation by national economies and improvement of bricks is of key interest to them.
\end{abstract}

Keywords: brick, black reduction core, efflorescence, calcium sulphate, micro X-ray fluorescence, Edax Eagle

\section{Contents}

1 Introduction 2

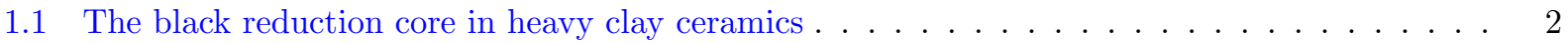

1.2 Source and composition of the raw clay used for brickmaking $\ldots \ldots \ldots \ldots$

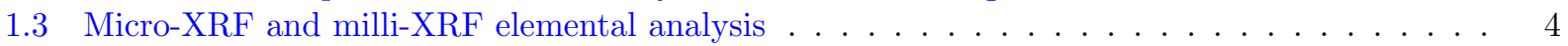

2 Materials and methods 6

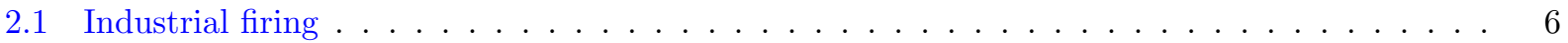

2.2 Inert firing atmosphere in laboratory furnace $\ldots \ldots \ldots \ldots \ldots \ldots \ldots \ldots$

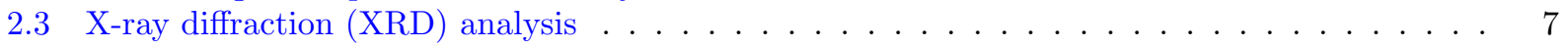

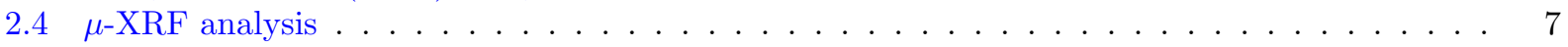

3 Results and discussion $\quad 8$

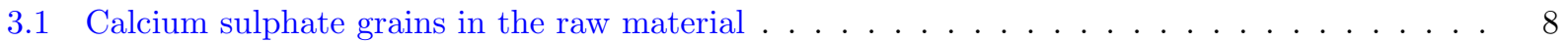

3.2 X-ray diffraction quantitative analysis of raw clay $\ldots \ldots \ldots \ldots \ldots$

3.3 X-ray diffraction patterns of material from the black core and red rim $\ldots \ldots \ldots$

3.4 Effect of inert firing atmosphere on colour development . . . . . . . . . . . . . . . 10

$3.5 \mu$-XRF sum spectrum on the mapping area $\ldots \ldots \ldots \ldots \ldots \ldots$

\footnotetext{
${ }^{*}$ Corresponding author

Email addresses: ludwig.gredmaier@web.de (L.Gredmaier), cjb@soton.ac.uk (C.J.Banks), r.pearce@noc.soton.ac.uk (R.B. Pearce)
} 
$3.6 \mu$-XRF mapping across the surface of a slice of brick . . . . . . . . . . . . . . . . . 10

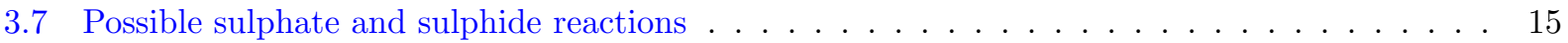

3.8 Sulphate salts in the brick life cycle . . . . . . . . . . . . . . . . . . . . . . 16

\section{Acknowledgements}

\section{Introduction}

The raw materials in the manufacture of bricks and tiles as well as in pottery are a mixture of clay, silt and sand, where particle size increases from clay to silt to sand. Physically, clays consist of minute flaky crystals that tend to form thin sheets which can be observed under a microscope. Chemically, clays consist mainly of silicon and aluminium - or since these elements usually occur as oxides, as silica and alumina - with smaller amounts of iron, calcium, sodium and other elements. In brick manufacture, the raw clay is mined, shaped into a brick in an extruder, dried to evaporate the water, and then fired in a kiln at a temperature typically between 900 to $1050^{\circ} \mathrm{C}$, where firing temperature is ideally tailored to the particular raw material used.

\subsection{The black reduction core in heavy clay ceramics}

Often, if a fired brick or tile is cut or broken apart, the centre of the fired clay body contains a black or grey core, which distinguishes it from the red colour of the rim or surface of the fired clay body. Such a black core can be found in many commercial bricks, roof and floor tiles to a greater or lesser extent. Figure 1 (and the top of Figure 9) show examples of a black core in a traditional but still widely used, solid English brick. Other expressions used for the presence of a black core like the one shown in Figure 1 are reduction core or black heart. The presence of a black reduction core in clay products is sometimes simply called black coring and it is a phenomenon that occurs in the firing of heavy clay products like bricks and ceramic sewage pipes, but also in contemporary pottery as well as archaeological pottery, e.g. in ancient pottery shards ([1] Garcia-Heras and Rincon 1996, [2] Pavia 2006).

It is often assumed that the black colour of the reduction core is caused directly by unburnt/unoxidised carbon, but when the red rim and black core are examined for carbon content, no difference in carbon content between rim and core can be detected ([3] MacKenzie and Cardile 1990). Also, black coring can still exist when low carbon clays are fired. It is now understood that black coring is not directly caused by unburnt carbon residues, but by reduced iron species ([4] Brownell 1957, [5] Barba et al. 1992, [6] Brosnan 2003, [7] Sveda 2006). Small quantities of carbonaceous matter can, however, promote the formation of black cores ([8] Otto 1979). Current knowledge is that black coring results from the reduction of iron oxide from hematite $\mathrm{Fe}_{2} \mathrm{O}_{3}$ to magnetite $\mathrm{Fe}_{3} \mathrm{O}_{4}$ during the firing process ([3] MacKenzie and Cardile 1990). Carbon monoxide may be stripping oxygen off hematite $\mathrm{Fe}_{2} \mathrm{O}_{3}$, leaving behind $\mathrm{Fe}_{3} \mathrm{O}_{4}$ - Figure 2. Gas diffusion is a two-way process. Oxygen needs to diffuse into the clay body during firing, and carbon monoxide and dioxide need to diffuse out of the clay body. So carbonaceous material is not directly responsible for the black core. However, it may be indirectly responsible for the black core by generating carbon monoxide that in turn reduces hematite $\mathrm{Fe}_{2} \mathrm{O}_{3}$ to magnetite $\mathrm{Fe}_{3} \mathrm{O}_{4}$. No other mineralogical changes appear to occur between black core and red rim. The following factors determine the extent of black reduction coring in fired clay ware:

- Firing time - a longer firing time can eliminate the black reduction core.

- The oxygen atmosphere during firing. Lack of oxygen promotes the formation of black reduction cores.

- Iron oxide content in the raw clay.

- Carbon content and burnout or oxidation of carbon during firing of the raw clay. 


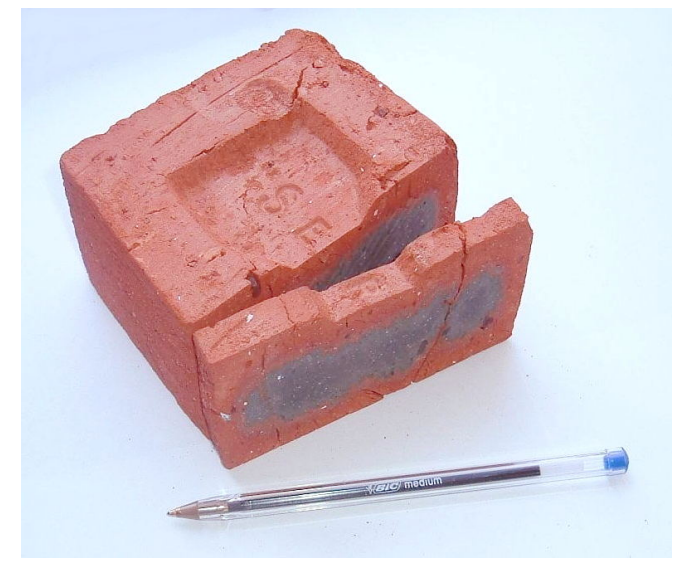

Figure 1: An industrially fired brick was cut apart and a slice about $10 \mathrm{~mm}$ thick was cut off from the middle of the brick. This $10 \mathrm{~mm}$ thick cross section of the brick was examined in a table top $\mu$-XRF analyser.

- Fineness of clay and degree of compaction which influences gas permeability: If gases do not have suffcient time to diffuse into or out of the interior of the brick during firing, the brick bloats ([9] Toledo et al. 2004).

- The degree of clay compaction and particle orientation in the brick extrusion press which aligns the clay particles normal to the compressive stress ([10] Fischer et al 1986). Gas exchange and gas development are different between clay powder and an extruded brick ([9] Toledo et al. 2004).

Black coring in bricks is a topic of interest for the following reasons:

- The black core is sometimes an undesirable optical feature in commercial products.

- The dark core and red rim reflect visible light differently and this may manifest a change in physical behaviour or chemistry between black core and red outer surface of the ceramic body. A black core may play a role in frost resistance and the compressive strength can be lower in bricks with a black core ([11] Sveda 2008), even though the presence of a reduction core on its own does not necessarily lead to an inferior product ([12] Elias 1980, [6] Brosnan 2003, [13] Brosnan 2009).

- The black core has occasionally been linked with a tendency for bloating of ceramic products during the firing process ([14] Butterworth and Honeyborne 1952).

- It has long been known that black coring can be eliminated by longer firing times ([15] Arnold and Duncombe 1929), but ceramic manufacturers aim for the shortest possible firing time or firing curve ([16] Holstrom 1981, [17] Funk 1982) in order to minimise fuel consumption.

- $\mathrm{CO}_{2}$ emissions of the ceramic industry are a matter of concern ([18] Agrafiotis and Tsoutsos 2001) and thus long firing times are prohibitive.

The authors originally expected to be able to pin down the strong visual effect of a black reduction core in chemical concentration terms, e.g. by detecting an iron gradient along a brick cross section that contained such a black reduction core. However, no such iron gradient was found, as will now be described.

\subsection{Source and composition of the raw clay used for brickmaking}

All clay raw materials were mined from the clay pit at the Tower Brick \& Tile company in Selborne, near Alton, Hampshire, in the South of England. The clay type is known as Gault clay and is of Cretacious origin with an estimated age of about 100 million years ([19] British Geological Survey 2007). Firing of bricks 


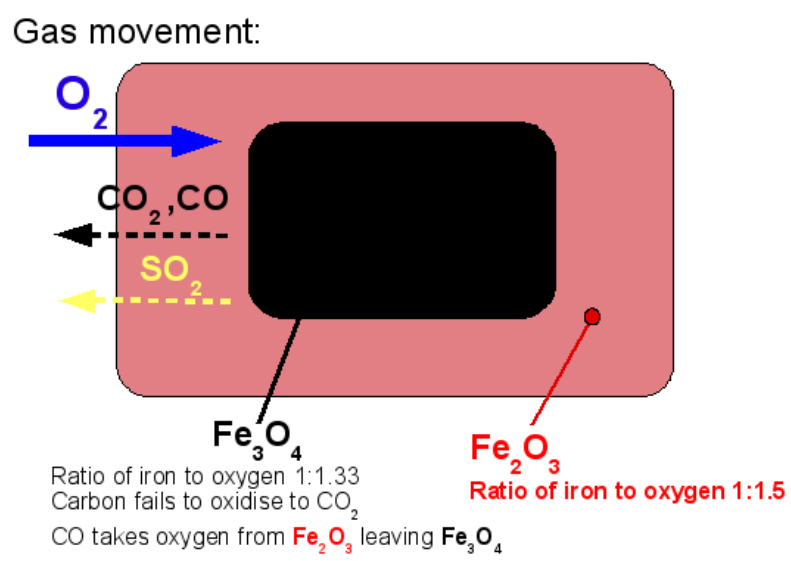

Figure 2: A simplified diagram of the processes causing a black reduction core in bricks. $\mathrm{CO}_{2}, \mathrm{CO}_{2} \mathrm{SO}_{2}$ and water vapour are gases that develop during firing of clay.

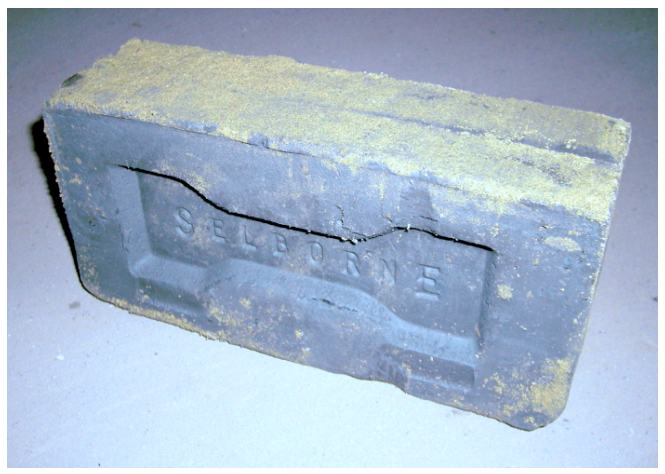

Figure 3: For elemental wavelength dispersive XRF-analysis of the clay, a dried brick was cut open and several grams of clay were taken out of the centre of the dried brick.

occurs in a commercial, natural gas fired kiln. Solid, classic, high quality English bricks of size $102.5 \times 215$ $\times 65 \mathrm{~mm}$ are manufactured. A raw, unfired brick is shown in Figure 3. Raw clay elemental composition before firing was investigated using standard wavelength dispersive X-ray fluorescence (WD-XRF) analysis as follows. A raw, green, unfired but dried brick was taken out of the production line at the Tower Brick \& Tile brick manufacturer - Figure 3. A slice of the dried, unfired brick was cut off and a few grams of the raw, dried clay were ground manually with a pestle and mortar. The clay powder was compressed into a pellet using a 'Herzog HP40' hydraulic press and analysed in a Philips Magix-Pro ${ }^{t m}$ PW-2540 WD-XRF (wavelength dispersive X-ray fluorescence) spectrometer with a $4 \mathrm{~kW}$ light element Rh-target to obtain the elemental composition of the clay raw material. The elemental composition of the raw, dried clay is listed in Table 1. Since the WD-XRF analysis is based on a pellet of compressed clay powder, it may therefore suffer from minor element matrix effects as well as orientation effects (e.g. [20] Gazulla et al 2008). The alternative analysis of clay powder in the form of fused disks was not advisable, because the high temperature used in the fusion process may destroy sulphur compounds in the clay, which are of interest here. From Table 1 it is clear that silica at $66 \%$ are dominant with alumina at $19 \%$ and substantial amounts of iron oxide at $8 \%$ in the raw, unfired clay material. Sulphur and calcium are very low at less than $1 \%$ by weight.

\subsection{Micro-XRF and milli-XRF elemental analysis}

In analytical chemistry some standard methods for mineral analysis are X-ray diffraction, Raman spectroscopy, mass spectrometry, FTIR (Fourier transform infrared) spectrometry. Unlike $\mu$-XRF, and with the 


\begin{tabular}{|c|c|c|}
\hline $\begin{array}{l}\text { Compound } \\
\text { or element }\end{array}$ & $\begin{array}{c}\text { proportion } \\
\text { (weight based) }\end{array}$ & - \\
\hline $\mathrm{SiO}_{2}$ & 66.2 & $(\%)$ \\
\hline $\mathrm{TiO}_{2}$ & 0.95 & (\%) \\
\hline $\mathrm{Al}_{2} \mathrm{O}_{3}$ & 19.13 & $(\%)$ \\
\hline $\mathrm{Fe}_{2} \mathrm{O}_{3}$ & 8.08 & (\%) \\
\hline $\mathrm{MnO}$ & 0.03 & (\%) \\
\hline$M g O$ & 2.15 & (\%) \\
\hline $\mathrm{CaO}$ & 0.5 & (\%) \\
\hline $\mathrm{K}_{2} \mathrm{O}$ & 2.94 & (\%) \\
\hline $\mathrm{Na}_{2} \mathrm{O}$ & 0.15 & (\%) \\
\hline$P_{2} O_{5}$ & 0.08 & $(\%)$ \\
\hline $\mathrm{S}$ & 0.12 & (\%) \\
\hline Co & 17.1 & (ppm) \\
\hline $\mathrm{Cr}$ & 148.4 & (ppm) \\
\hline V & 171 & (ppm) \\
\hline $\mathrm{Ni}$ & 24.4 & (ppm) \\
\hline $\mathrm{Cu}$ & 23.1 & (ppm) \\
\hline $\mathrm{Zn}$ & 93.2 & (ppm) \\
\hline $\mathrm{Pb}$ & 23 & (ppm) \\
\hline $\mathrm{Ba}$ & 324.5 & (ppm) \\
\hline $\mathrm{Rb}$ & 117.2 & (ppm) \\
\hline $\mathrm{Sr}$ & 110.5 & $(\mathrm{ppm})$ \\
\hline Y & 24.1 & $(\mathrm{ppm})$ \\
\hline $\mathrm{Zr}$ & 245.9 & $(\mathrm{ppm})$ \\
\hline $\mathrm{Nb}$ & 24 & $(\mathrm{ppm})$ \\
\hline Th & 10.3 & $(\mathrm{ppm})$ \\
\hline U & 3.8 & (ppm) \\
\hline La & 44.6 & $(\mathrm{ppm})$ \\
\hline $\mathrm{Ce}$ & 105.4 & $(\mathrm{ppm})$ \\
\hline $\mathrm{Ga}$ & 21.3 & (ppm) \\
\hline As & 19.4 & (ppm) \\
\hline Sum & 100.49 & $(\%)$ \\
\hline
\end{tabular}

Table 1: Wavelength dispersive XRF analysis of the raw clay powder taken out of a green brick after drying. The clay was pressed into a pellet for elemental analysis. Sulphur and calcium, are very low in concentration. Trace elements are likely to be accurate, but due to orientation effects of the powder sample the three oxides $\mathrm{SiO}_{2}, \mathrm{Al}_{2} \mathrm{O}_{3}$ and $\mathrm{MgO}$ are probably slightly overestimated. 


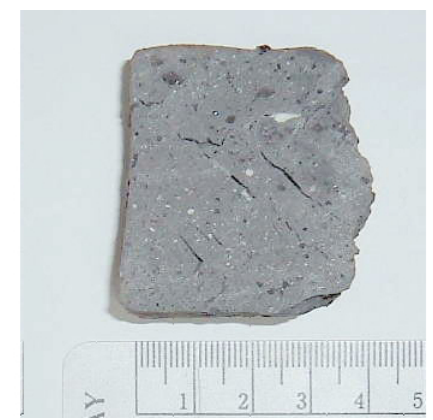

Figure 4: A raw, dried brick was cut to size to fit into a laboratory tube furnace and fired at $1050^{\circ} \mathrm{C}$ in inert argon gas. Shown is a slice cut off after firing.

exception of Raman spectroscopy, all these analytical methods are not in-situ methods. Also, their detection limits - with the exception of mass spectrometry, which has excellent detection limits but is not an in-situ method - are not sufficient for low elemental quantities in the range of $0.5 \%$ by weight (e.g. [21] Bitossi et al. 2005, [22] Manso and Carvalho 2009). In $\mu$-XRF analysis the sample is scanned across the surface with an $\mathrm{X}$-ray beam, and the elemental composition and spatial distribution of the elements is determined. The term 'micro' depicts the minimum lateral (spatial) resolution of the X-ray beam of the instrument which can be down to several micrometers with the most modern desktop instruments. For the elemental analysis reported in this paper, the sample is comparatively large at several $\mathrm{cm}^{2}$, and thus there was no need for micrometer lateral resolution, and the more precise term would therefore be 'milli-XRF' rather than micro-XRF ([23] Davis et al. 2009). However, due to the ubiquitous use of the term micro-XRF ( $\mu$-XRF), we also use the term in this work, even though it is not quite correct. To create an elemental image, a sample is analysed multiple times, as a matrix of equally spaced points on the sample surface. For each matrix point of the sample surface a complete XRF spectrum is acquired. From the XRF spectrum at each data point the peak of the chemical element, also known as ROI (region of interest), is used to generate images. The image pixel intensities are calculated based on the XRF intensity. Each image pixel for a certain element is extracted from the parent XRF-spectrum at that point on the sample surface.

\section{Materials and methods}

Two X-ray fluorescence analysis methods were used. The bulk elemental analysis, based on WD-XRF (wavelength dispersive X-ray fluorescence) of the raw clay used for brick manufacture is listed in Table 1. The second X-ray analytical method is known as energy dispersive $\mu$-XRF, which allowed in-situ analysis of a brick slice after firing to observe elemental gradients (rather than bulk analysis) on the surface of the brick slice.

\subsection{Industrial firing}

The brick sample slices subjected to $\mu$-XRF analysis were fired in an industrial chamber kiln with natural gas as fuel. The firing temperature was $1050^{\circ} \mathrm{C}$ and the temperature is held there for 15 hours.

\subsection{Inert firing atmosphere in laboratory furnace}

To confirm that the firing atmosphere determines the colour development of the clay, laboratory firings were undertaken with smaller sized brick portions. A dried brick was taken out of the industrial production line and a piece cut to size to fit into a laboratory tube furnace of $8 \mathrm{~cm}$ inner diameter. The firing curve was idential to the one for the industrial kiln firing, but no oxygen was available in the firing process since the laboratory furnace was flushed with a steady stream of inert argon gas. After firing the brick piece was cut apart for visual inspection and $\mu$-XRF analysis - Figure 4. 


\subsection{X-ray diffraction (XRD) analysis}

$\mathrm{X}$-ray diffraction analysis was performed on three samples: (i) The unfired, but dried raw clay material used to make bricks; (ii) material from the black core of a fired brick and (iii) material from the red rim of a fired brick. Sample preparation for X-ray diffraction analysis was as follows. The coarse clay powder or fired brick material was crushed manually in a mortar into smaller pieces and then sieved through a sieve with mesh size $0.5 \mathrm{~mm}$. This powder was ground in propanol for 8 minutes to $1 \mu \mathrm{m}$ or smaller, using a McCrone micronising mill. The sample was left on a hot plate over night at $60^{\circ} \mathrm{C}$ to evaporate the propanol. The resulting sample should consist of particles of about $1 \mu \mathrm{m}$ size. Two well-known XRD sample preparation methods were employed:

1. Powder diffraction method: The bulk analysis was carried out on a powder sample where the powder particles are oriented in random positions in the X-ray diffraction analysis. The X-ray diffraction tracing from the randomly ordered powder provides an estimate of the proportion of clay and non-clay minerals (e.g quartz, feldspars, carbonates, gypsum, pyrite, iron oxides). The disadvantage of the random orientation powder method is, that the non-clay minerals will mask some of the reflections of the clay minerals. Specific clay minerals can therefore not be identified with certainty in the powder diffraction method ([24] Moore and Reynolds 1997).

2. Oriented smear sample method: Used to identify and quantify individual clay minerals. The raw brick clay sample was gently broken up in a pestle and mortar and added to MilliQ water. Five ml of $5 \%$ solution sodium hexametaphosphate was added to assist dispersion of the clay particles. The solution was centrifuged for 3 minutes at 750 r.p.m. allowing the coarser than 2 micron fraction to settle out. The solution was decanted into another centrifuge tube, $5 \mathrm{ml}$ of a $5 \%$ solution of $\mathrm{MgCl}_{2}$ was added and topped up with MilliQ deionised water, and centrifuged at 1500 r.p.m. The supernatant liquid was decanted off and the process repeated, once with $5 \% \mathrm{MgCl}_{2}$ solution and twice thereafter with just MilliQ water. The samples were smeared on glass slides and allowed to dry overnight at ambient temperature. The clay samples were run on the XRD as an air-dried sample $\left(2-15^{\circ} 2 \Theta\right)$, after ethylene glycol solvation overnight $\left(2-40^{\circ} 2 \Theta\right)$, heating to $375^{\circ} \mathrm{C}\left(2-15^{\circ} 2 \Theta\right)$ and after heating to $550^{\circ} \mathrm{C}\left(2-15^{\circ}\right.$ $2 \Theta)$. All four XRD traces were used for a single quantitive analysis.

All X-ray diffraction patterns were recorded on a Philips X'Pert Pro diffractometer at the National Oceanography Centre, Southampton, using $C u K \alpha$ radiation $(35 \mathrm{kV}, 40 \mathrm{~mA})$ at angles from 2 to $78^{\circ}$ with a step size of $0.02^{\circ}$ and acquisition time $1.2 \mathrm{~s}$ per step. Mineral phases were qualitatively identified with the Philips XPert software, which is based on the PDF database from the JCPDS (Joint Committee on Powder Diffraction Standards). For quantitative bulk analysis, bespoke software was used, employing a FULLPAT approach ([25] Chipera and Bish 2002), where $25 \%$ of artificial corundum by weight is added to the sample, and where the (known) corundum peak height in the XRD pattern is used to quantify the remaining peaks. The clay fraction was quantified using method based on [26] Biscaye 1965.

\section{4. $\mu-X R F$ analysis}

A desktop $\mu$-XRF analyser 'Edax Eagle III' was used (www.edax.com). The individual spectra were recorded in vacuum with a measuring time/dwell time of $10 \mathrm{~s}$ per pixel and with a spatial resolution of 300 $\mu \mathrm{m}$ horizontally and vertically. This results in a total analysis time of 12800 pixels times $10 \mathrm{~s}$ dwell time $=$ $128000 \mathrm{~s}=36$ hours total surface analysis time. Each elemental map consisted of $128 \times 100=12800$ pixels with single colour or greyscale intensities from 0 to 255. The 'Edax Eagle III' is fitted with a 40-300 $\mu$ m glass polycapillary/varifocus X-ray waveguide and the maximum possible spot size of $300 \mu \mathrm{m}$ was used. Excitation voltage was $40 \mathrm{kV}$ in a $50 \mathrm{~W} \mathrm{X}$-ray tube with $\mathrm{Rh}$ as target material. The detector is a liquid nitrogen cooled $\mathrm{Si}(\mathrm{Li})$ solid-state energy dispersive X-ray detector with $140 \mathrm{eV}$ spectral resolution at $\mathrm{MnK} \alpha$. The size of the analysis area on the brick slice sample surface was $34 \mathrm{~mm} \times 26.5 \mathrm{~mm}$ - see outline at the top of Figure 9. All element mappings were element-count maps rather than quantification maps. The 'Edax Eagle III' has the option of element quantification using the [27] Lucas-Tooth and Pyne 1964 algorithm (also [28] Lucas-Tooth and Price 1961, [29] Tertian and Claisse 1982, p. 168) to the spectral data, but this option was not used here, mainly because quantification employs higher detection thresholds than qualitative analysis based on elemental peak areas. 


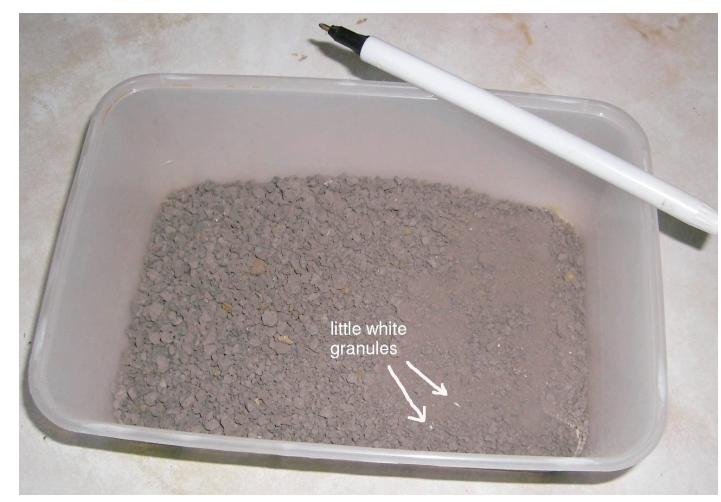

Figure 5: Dried raw material used for brickmaking. Little white grains were discernable by eye. Using X-ray diffraction, these grains were identified as a mixture of calcium sulphate hydrate $\mathrm{CaSO}_{4} \frac{1}{2} \mathrm{H}_{2} \mathrm{O}$ and quartz.

\section{Results and discussion}

\subsection{Calcium sulphate grains in the raw material}

Dried clay powder extracted from the interior of an extruded, unfired brick obtained from the Tower Brick \& Tile company is shown in Figure 5. The powder was used to obtain samples for the random-orientation Xray diffraction analysis and the oriented X-ray diffraction analysis (smear sample). Small white grains were discernable with the naked eye. Running these small, white grains through the XRD-analyser in powder form, they were identified as a mixture of calcium sulphate hydrate $\mathrm{CaSO}_{4} \frac{1}{2} \mathrm{H}_{2} \mathrm{O}\left(\right.$ similar to gypsum $\left.\mathrm{CaSO}_{4} 2 \mathrm{H}_{2} \mathrm{O}\right)$ and quartz $\mathrm{SiO}_{2}$.

\subsection{X-ray diffraction quantitative analysis of raw clay}

From the XRD powder analysis, the quartz content is large at $31.6 \%$ by weight ${ }^{1}$. Total clay content was $62.5 \%$. Of interest is the presence of plagioclase with $0.6 \%$, since it represents a calcium source. The concentration of K-feldspar was $2.2 \%$ in the raw material. A further analysis of the $<2 \mu m$ clay fraction was conducted. The oriented smear slide XRD method revealed that the clays from the random orientation powder analysis consisted of the following clay types: $29 \%$ kaolinite, $34 \%$ illite, $30 \%$ smectite and $7 \%$ vermiculite. The largest clay fraction is illite which is known to consist of very fine particles that inhibit gas diffusion during the firing process. In a word, the mineralogy is complex with almost similar amounts of illite, kaolinite and smectite, and a trace of vermiculite. Similar compositions of English Gault clay have been reported by [30] Freeman 1964.

\subsection{X-ray diffraction patterns of material from the black core and red rim}

Figure 6 shows the X-ray powder diffraction patterns for material taken out of a fired brick from the black core (lower black graph), and the red rim (upper red graph). It is clear that quartz lines (magenta coloured vertical lines) dominate the pattern strongly for both the black core and the red rim. The 2nd strongest lines for the red rim XRD-pattern are indeed those of hematite $\mathrm{Fe}_{2} \mathrm{O}_{3}$ (red vertical lines). Clay peaks that dominated the unfired raw material ${ }^{2}$ completely disappear, due to firing transformations, into a glassy, amorphous phase (e.g. [31] Gonzalezgarcia et al., 1990 [32] Jordan 1999). For the XRD pattern of the black core - bottom graph of Figure 6, no pure magnetite lines were found, but a spinel-type phase at slightly higher diffraction angles. To illustrate the theoretical diffraction angle positions of pure magnetite (using powder diffraction file PDF data for pure magnetite), cyan coloured stars have been plotted into the lower black graph of Figure 6. Magnetite and spinels have isomorphous crystal structures and it appears

\footnotetext{
${ }^{1} \mathrm{XRD}$ traces are not shown.

${ }^{2} \mathrm{XRD}$ trace of the raw material not shown. The clay concentration in the raw material was around $62.5 \%$.
} 


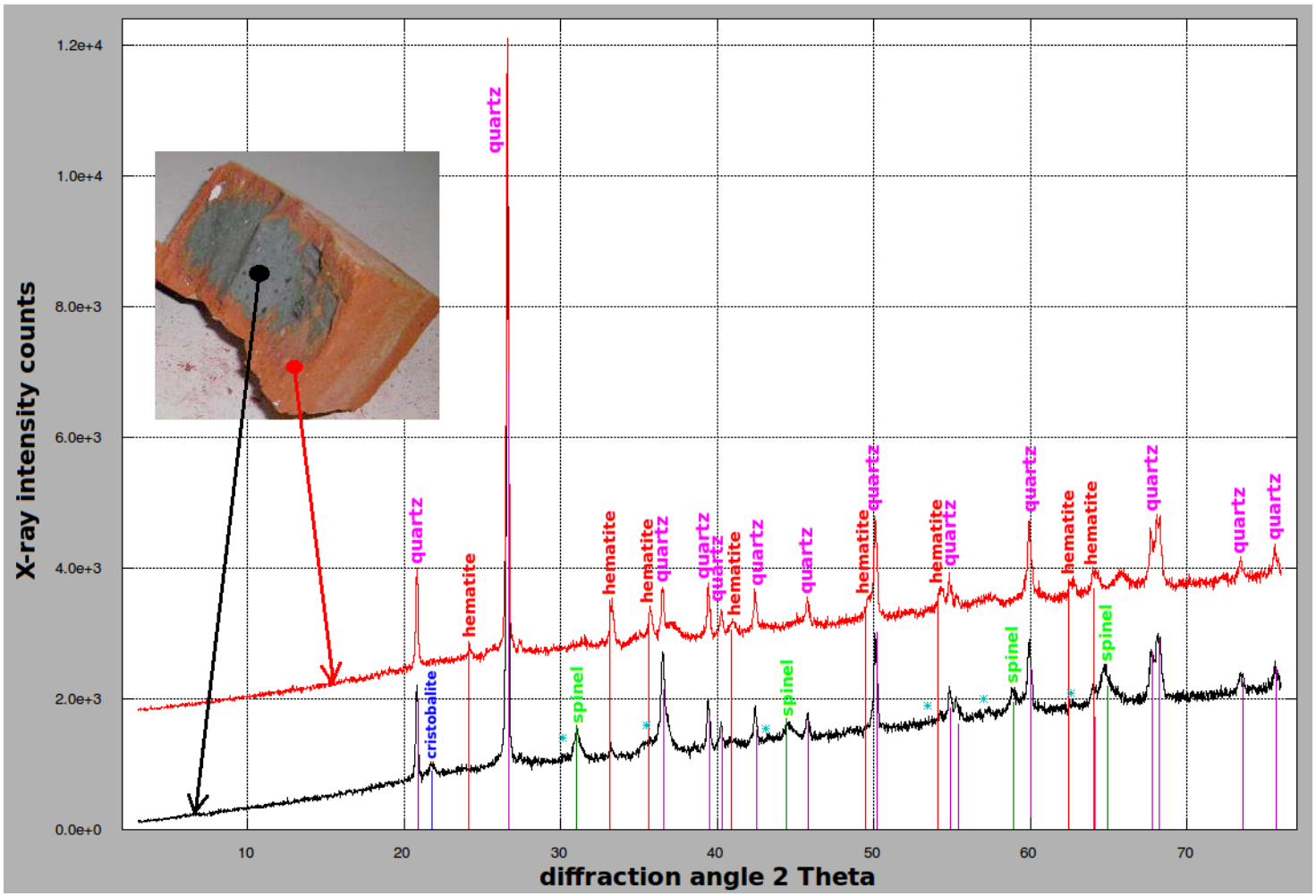

Figure 6: Powder X-ray diffraction patterns of samples taken out of a fired brick from the black core (lower black graph) and the red rim (upper red graph). The XRD pattern for the black core the has been shifted vertically to allow better comparison. The cyan coloured stars represent the six largest lines for pure magnetite $\mathrm{Fe}_{3} \mathrm{O}_{4}$, that were expected in the black graph, but were not present at these positions. 
that the magnetite unit cell is distorted by the firing process and that elements other than iron have replaced Fe-ions in the magnetite unit cell.

The quality of the XRD analysis is very high in terms of horizontal peak position, as the actual quartz peaks are extremely close to the positions where theoretical pure quartz lines are known to occur. This would support the assumption that the spinel found in the black core XRD pattern represents unit cell distorted magnetite lines. In essence, synthetic hematite was found in abundance in the red rim, and a spinel that is likely to contain magnetite could be identified in the black core when powder X-ray diffraction was performed on material taken from a fired brick.

\subsection{Effect of inert firing atmosphere on colour development}

If the firing atomsphere lacks oxygen, no red colour develops - Figure 4. The brick material remains in a dark grey colour both inside and outside the fired brick piece. The grey colour is uniform and apart from local, granular inclusions, no large-scale gradients are discernible by eye. The inert-gas fired piece was also $\mu$-XRF analysed, but as expected, due to the absence of oxygen, no large-scale elemental gradients along the cross section were found, even when the $\mu$-XRF surface dwell time was long.

\section{5. $\mu-X R F$ sum spectrum on the mapping area}

The sum spectrum resulting from the $\mu$-XRF maps is plotted in Figure 7. The y-axis represents X-ray counts and is logarithmic in Figure 7 to accommodate a wide range of count rates (peak magnitudes). The sum spectrum is the sum of all individual pixel spectra used to generate the elemental maps of Figure 8. Since the effect of summing up individual pixel spectra is that the spectral noise gradually averages out, the sum spectrum is very clear with extremely low noise. All peaks are due to electron transmissions from the L-shell into the K-shell, known as K $\alpha$ peaks. The only exception is the peak for $\mathrm{Pb}$ which is a $\mathrm{L} \alpha$ peak, caused by a transition of electrons from the M-shell to the L-shell. This is the sum spectrum of the area shown at the top of Figure 9. The Rh peaks are artefacts caused by the X-ray tube target material (Rh-target). They are not caused by $\mathrm{Rh}$ in the brick sample. Due to the long averaging times numerous elements are detectable. The dominant peak is that of iron at $6.40 \mathrm{keV}$. A comparatively large sum peak caused by iron can be observed at twice the energy of iron: $2 \times 6.40 \mathrm{keV}=12.80 \mathrm{keV}$. A Compton peak due to X-ray scatter is observed at around $18 \mathrm{keV}$. Scattering is known to be substantial with ceramic matrices. The $\mathrm{S}(\mathrm{K} \alpha)$ and the $\mathrm{Ca}(\mathrm{K} \alpha)$ peaks are clearly observable at $2.31 \mathrm{keV}$ and $3.69 \mathrm{keV}$ respectively (Figure 7). The area under these peaks in the individual pixel spectra is used to generate the Ca and S maps of Figure 8 and left hand side of Figure 9. All named peaks in Figure 7 are $\mathrm{K} \alpha$ (electron) transitions apart from the $\mathrm{Pb}$ peak which is an L-peak. The K-lines of lead are above the Rh energy and therefore can not be excited by $\mathrm{Rh}$ radiation. The $\mathrm{K} \alpha$ line for sulphur occurs at $2.31 \mathrm{keV}$ and the $K \alpha$ line for calcium occurs at 3.69 $\mathrm{keV}$ (Figure 7). Because spectral resolution of the energy dispersive XRF instrument is only about $140 \mathrm{eV}$ FWHM (full width half magnitude), it is not always possible to differentiate between $\mathrm{K} \alpha$ and $\mathrm{K} \beta$ lines for the lighter elements. No X-ray filter has been applied in the instrument to filter out unwanted Rh energies. The spectral line at about $2.6 \mathrm{keV}$ is caused by $\mathrm{Rh} \mathrm{L} \alpha$ energy scattered from the brick surface, and it would be interesting to look at the scattering effect closer, since the black core seems to scatter slightly different than the red rim of the brick cross section, but this has not been investigated further. ${ }^{3}$

\section{6. $\mu$-XRF mapping across the surface of a slice of brick}

A commercially fired, solid brick was cut into a slice - Figure 1 and the brick slice surface $\mu$-XRF maps are displayed in Figure 8 for the elements $\mathrm{Al}, \mathrm{Ca}, \mathrm{Cr}, \mathrm{Cu}, \mathrm{Fe}, \mathrm{Mn}, \mathrm{Ni}, \mathrm{Pb}, \mathrm{Rb}, \mathrm{Si}, \mathrm{S}, \mathrm{Ti}, \mathrm{U}$ and $\mathrm{Zn}$. The maps are so-called region-of-interest (ROI) maps rather than quantification maps, i.e. the spectral peak areas are linearly converted (or mapped) into the greyscale values from 0 to 255. This means matrix effects of, for example, iron, are not corrected for. For example, iron grains, that occur in the brick analysis surface as

\footnotetext{
${ }^{3}$ The $\mathrm{Cl} \mathrm{K} \alpha$ line is at $2.622 \mathrm{keV}$ whereas the $\mathrm{Rh} \mathrm{L} \alpha$ line is at $2.696 \mathrm{keV}$, and the two lines are easy to confuse, as pointed out by a careful reviewer.
} 


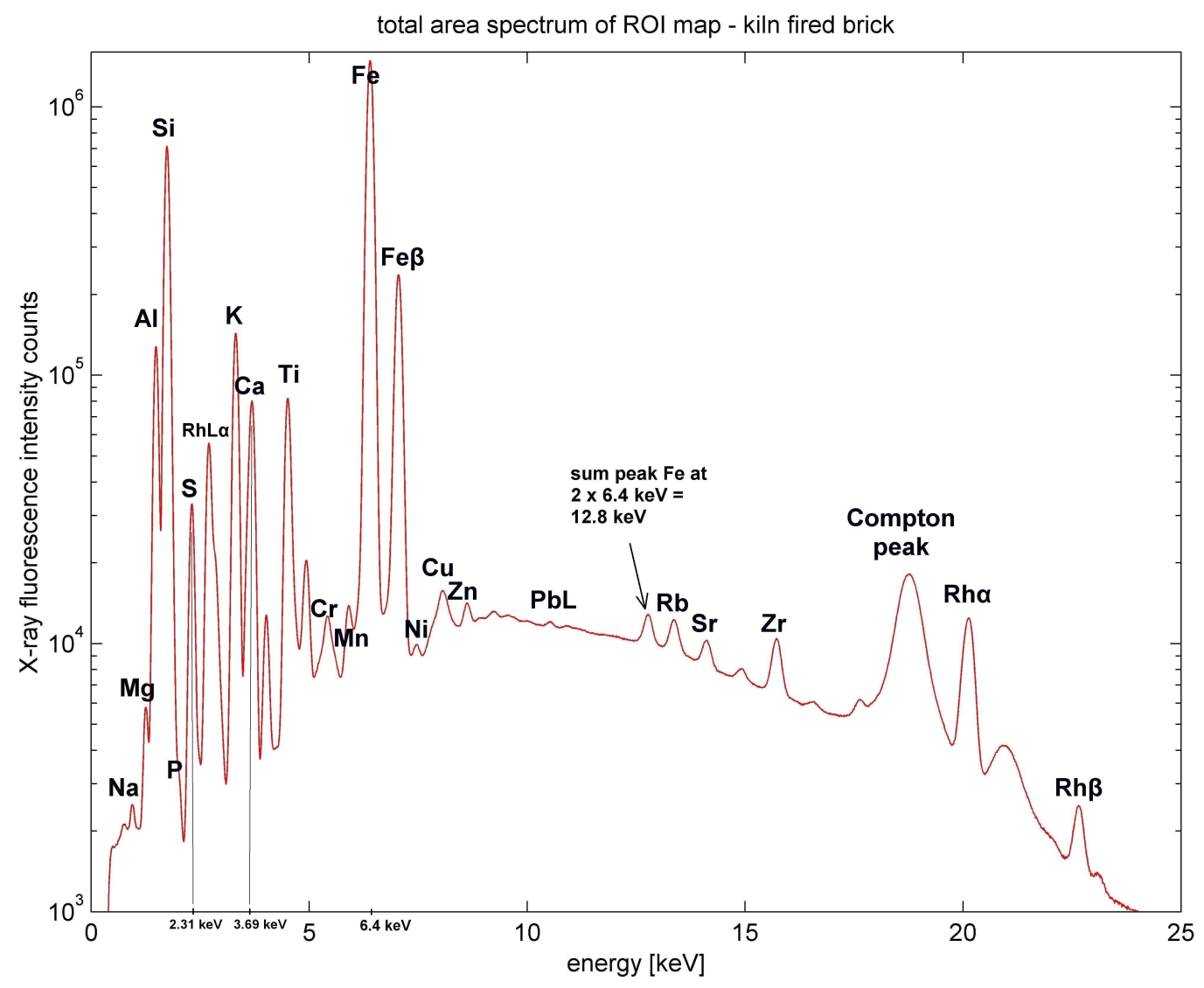

Figure 7: Sum spectrum of all individual pixel spectra collected in the 36-hour $\mu$-XRF mapping. 


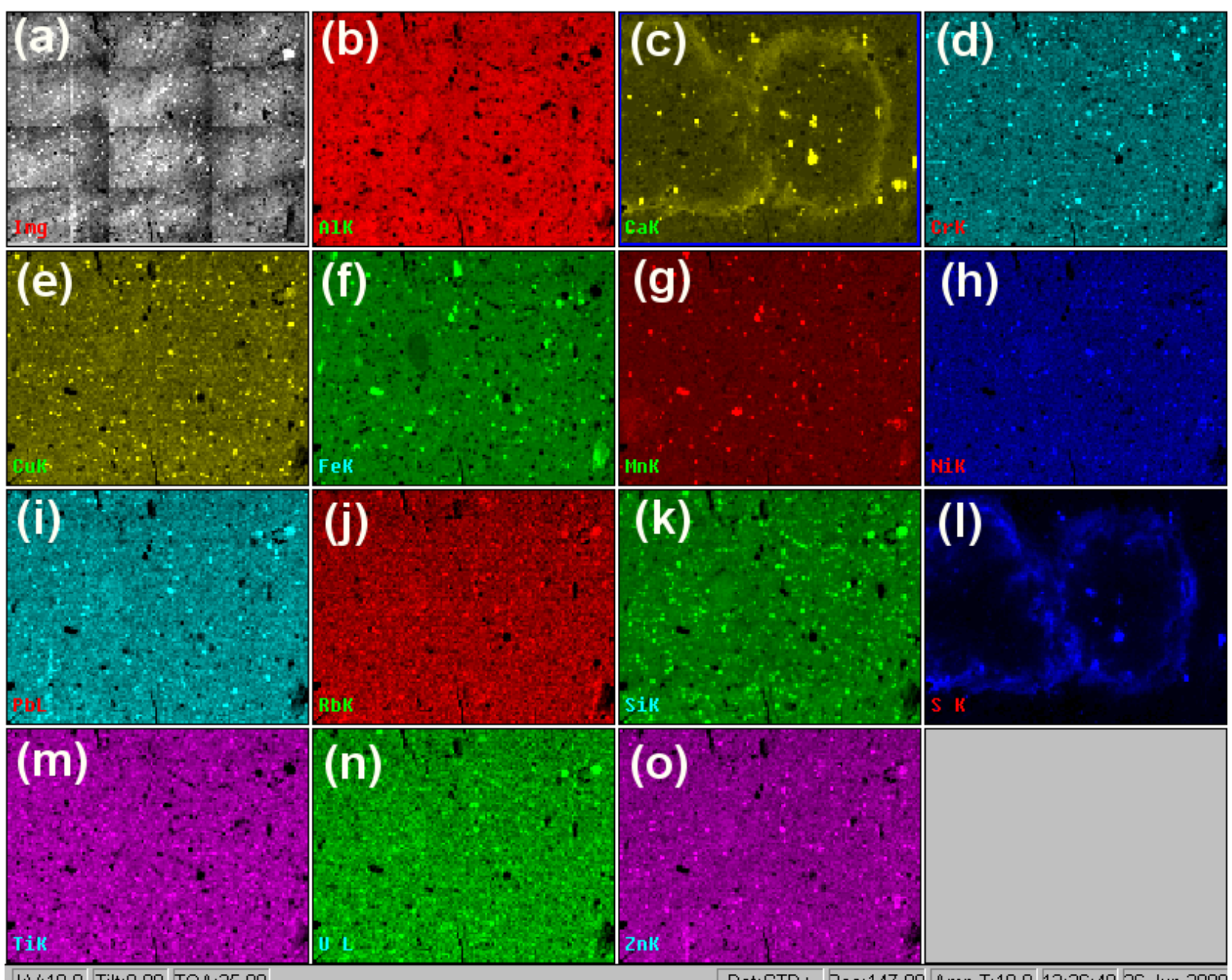

Figure 8: Elemental distribution of various elements ( $\mu$-XRF analysis) of a slice of brick. The brick slice is shown in Figure 1 and at the top of Figure 9. The scanned surface is the one marked with a thick white line in the top of Figure 9. The distribution of the elements $\mathrm{Al}, \mathrm{Ca}, \mathrm{Cr}, \mathrm{Cu}, \mathrm{Fe}, \mathrm{Mn}, \mathrm{Ni}, \mathrm{Pb}, \mathrm{Rb}, \mathrm{Si}, \mathrm{S}, \mathrm{Ti}, \mathrm{U}$ and $\mathrm{Zn}$, labelled (b) to (o) in alphabetical order, is shown.

inclusions would attenuate lower $\mathrm{Z}$ element fluorescence drastically. This matrix effect is neglected in ROI maps. The very first map in Figure 8, map (a), is a black and white image of the analysis area of the brick slice. The $\mu$-XRF analysis area is shown in better quality at the top of Figure 9.

All individual element maps in Figure 8 are based on peak areas of a ROI in the XRF spectrum rather than quantification maps. For $\mu$-XRF mapping, the $\mathrm{K}$-lines were used for $\mathrm{Al}, \mathrm{Ca}, \mathrm{Cr}, \mathrm{Cu}, \mathrm{Fe}, \mathrm{Mn}, \mathrm{Ni}, \mathrm{Rb}$, $\mathrm{Si}, \mathrm{S}, \mathrm{Ti}$, and $\mathrm{Zn}$. Only for the $\mathrm{Pb}$ and $\mathrm{U}$ elemental maps the L-line was employed for mapping, as the K-line for $\mathrm{Pb}$ and $\mathrm{U}$ can not be excited by $\mathrm{Rh}$. The images in Figure 8 are colourised 8-bit greyscale images, where one image pixel can take on brightness values between 0 and 255, proportional to the elemental peak area in the XRF spectrum. Brighter pixels represent higher concentrations.

In the discussion of the $\mu$-XRF maps it is useful to differentiate between (1) small-scale elemental gradients, caused by local inclusions of, for example, quartz grains, in the brick body, and (2) large-scale element gradients, that are evident on the whole cross section of the brick slice. The individual $\mu-X R F$ maps for the elements $\mathrm{Al}, \mathrm{Cr}, \mathrm{Cu}, \mathrm{Fe}, \mathrm{Mn}, \mathrm{Ni}, \mathrm{Pb}, \mathrm{Rb}, \mathrm{Si}, \mathrm{Ti}, \mathrm{U}$ and $\mathrm{Zn}$ only show small-scale gradients due to local inclusions like shiny quartz grains or white gypsum (calcium-sulphate) grains. These iron, quartz 


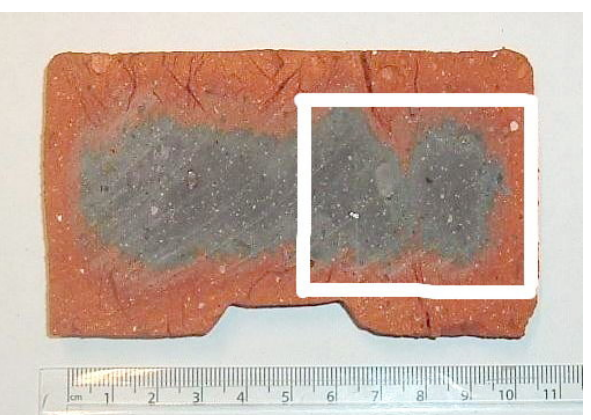

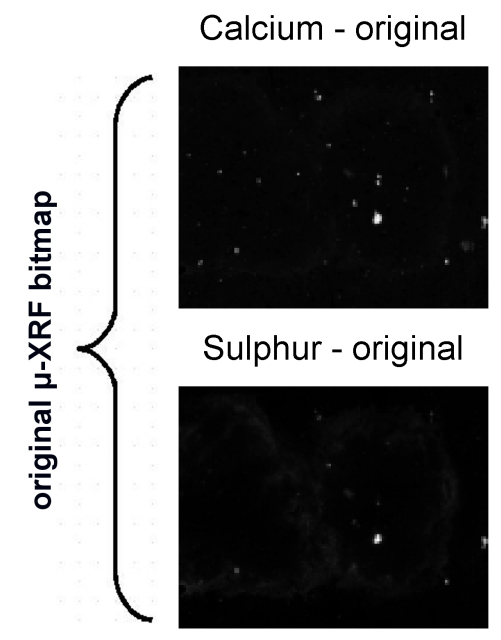

Calcium - equalized

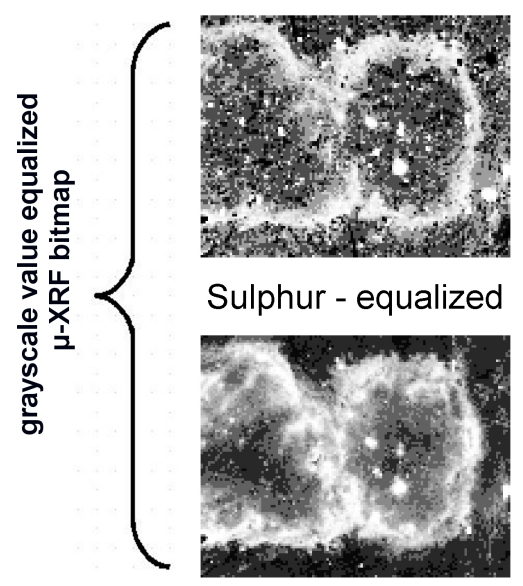

histogram 256 bins
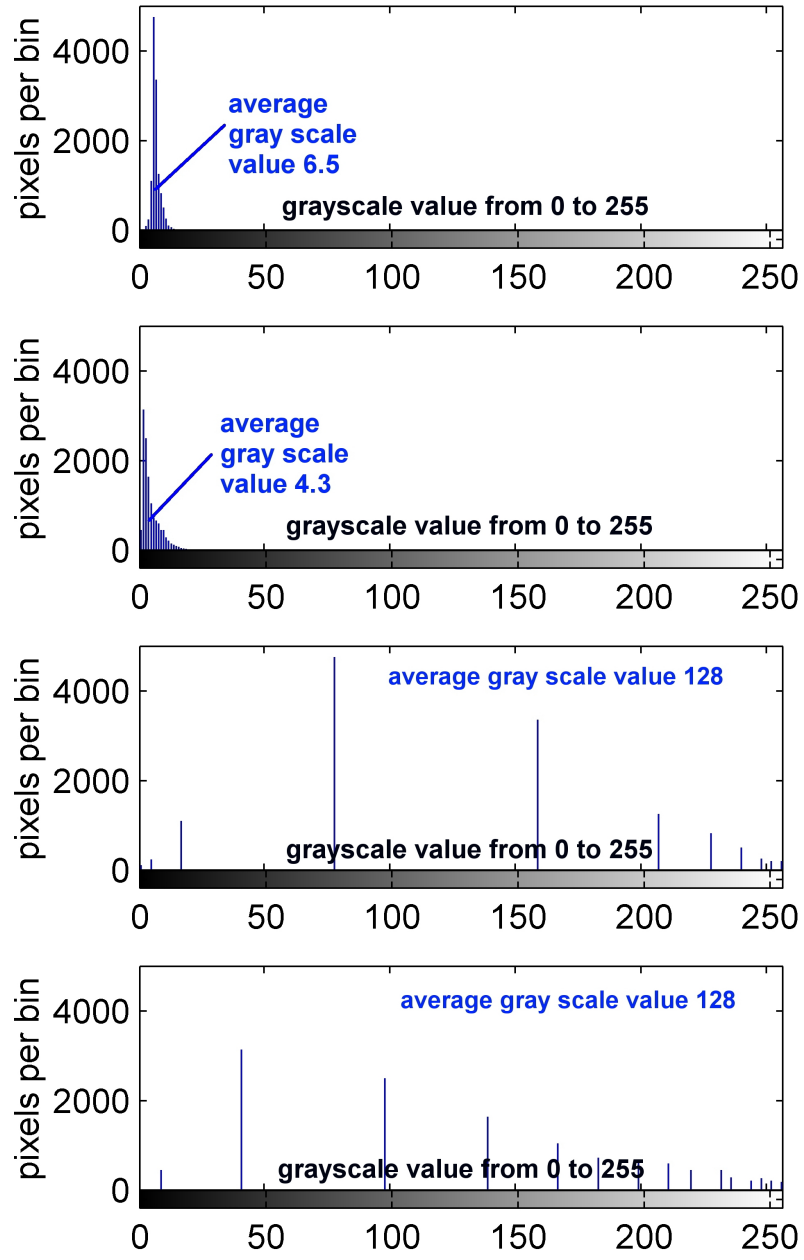

Figure 9: Top: Photograph of the brick slice on which the $\mu$-XRF maps were done. The area marked with a thick white line is the analysis area (mapping area). The resulting original and histogram equalized greyscale images of the calcium and sulphur scan are shown on the left. Brighter pixels represent higher concentrations. The image pixel intensity histograms corresponding to the $\mu$-XRF maps on the left are plotted on the right hand side. 
and gypsum inclusions result in the granular pattern of most of the $\mu$-XRF maps. In the map for iron Fe, map (f) in Figure 8, the granular pattern is due to iron oxide grains that occur irregularly in the raw clay. Similarly, in the map for calcium, map (c) in Figure 8, the granular pattern is due to gypsum grains that were present in the raw clay prior to firing and have not been destroyed at the firing temperature of $1050^{\circ} \mathrm{C}$. Similar granular patterns due to local inclusions, are visible in all maps of Figure 8.

There are only two $\mu$-XRF maps in Figure 8 with a large-scale gradient across the whole surface of the mapping area: These two large-scale gradients are those of calcium and sulphur - map (c) and map (l) in Figure 8. All elements other than $\mathrm{Ca}$ and $\mathrm{S}$ only exhibit small-area gradients due to local inclusions, like iron or sand $/ \mathrm{SiO}_{2}$ grains.

It is clear that both calcium and sulphur have accumulated at the transition area between the red outer rim and the black core of the brick. It can be assumed that $\mathrm{Ca}$ and $\mathrm{S}$ have combined to form calcium sulphate $\mathrm{CaSO}_{4}$ anhydrite. The maps for $\mathrm{Ca}$ and $\mathrm{S}$ in Figure 8 have been re-plotted in the left hand side of Figure 9 to illustrate the low pixel brightness values in the $\mathrm{Ca}$ and $\mathrm{S}$ elemental maps. Several polymorphs of calcium sulphate exist, but since the firing temperature was $1050^{\circ} \mathrm{C}$ no hydroxyls in $\mathrm{CaSO}_{4}$ can be present. From Table 1 it is clear that $\mathrm{Ca}$ and $\mathrm{S}$ were low in concentration in the raw clay at about $0.5 \%$ (weight basis). Yet the very clear formation of a $\mathrm{CaSO}_{4}$ zone around the black core is noteworthy, and has, to the authors' knowledge not been reported before. It is likely that the main Ca source for the Ca and $\mathrm{S}$ zoning observed around the black core - Figure 9 is plagioclase, which was observed in the raw material powder XRD at 0.6 $\%$.

To explain the calcium sulphate formation observed around the black core in brick firing, it is helpful to look into other engineering applications where $\mathrm{CaSO}_{4}$ reactions occur. In flue gas desulphurisation in coal fired power stations, calcium carbonate and $\mathrm{CaO}$ are added to the coal furnace. Coal can have substantial amounts of sulphur, and the sulphur has to be stripped from the flue gases before releasing the exhaust gases into the atmosphere, to avoid gaseous $\mathrm{SO}_{2}$ and thus acid rain formation. The CaO and $\mathrm{S}$ combine at high temperature to form $\mathrm{CaSO}_{4}$, i.e. bind sulphur from the fuel onto $\mathrm{Ca}$ or CaO. The reaction of calcium/calcium carbonate with sulphur dioxide has been researched actively in flue gas desulphurisation (e.g.[33] Fernandes et al 2000). A substantial amount of $\mathrm{CaSO}_{4}$ is generated in flue gas desulphurisation. An identical process could occur when a brick is fired, where the $\mathrm{Ca}$ is present originally as calcium carbonate in the raw clay, and reacts with $\mathrm{S}$ after $\mathrm{CO}_{2}$ has been driven off at 800 to $900^{\circ} \mathrm{C}$.

The $\mu$-XRF maps of $\mathrm{Ca}$ and $\mathrm{S}$ in Figure 8 are colourized greyscale images. The $\mu$-XRF maps of Ca and $\mathrm{S}$ of Figure 8 were analysed in more detail in Figure 9. The four bitmaps on the left hand side of Figure 9 are the same maps as map (c) and map (l) in Figure 8, but with the following differences: Firstly they are true greyscale images with 8-bit resolution, i.e. with pixel greyscale values from 0 to 255 , rather than colourised images. Second, the bottom two left hand side bitmaps for Ca and S in Figure 9 have been adjusted or digitally processed to yield an average greyscale value of 128 plus a more even spread across the greyscale range (0 to 255). The process of adjusting the greyscale values of the original bitmap image to values that are approximately in the middle of the greyscale range is to improve the visualisation of elemental gradients. The top two left hand side bitmaps are the original bitmaps that came out of the $\mu$-XRF mapping process - no digital image processing is applied. The typical or average greyscale value, which corresponds to the $\mathrm{X}$-ray intensity of the secondary radiation from the sample, is very low. In the original Ca $\mu$-XRF map, the greyscale intensity is typically between 6 and 7 (statistical mean is 6.5 for Ca). Similarly, with the original $\mathrm{S} \mu$-XRF map, the greyscale intensity is typically between 4 and 5 (statistical mean is 4.3 for the $\mathrm{S}$ map). It may help to review the X-ray fluorescent effect here. Primary X-rays are radiated onto the surface of the brick slice by the X-ray tube. These primary X-rays result in secondary X-rays in the brick surface, and these secondary X-rays are picked up by the X-ray detector. In the case of Ca and S X-ray K $\alpha$-energies, the X-ray intensity counts are so low, that they are just about detectable. Low secondary X-ray intensities yield low greyscale values, and this is the reason why the two left hand side images of Figure 9 appear to be almost black to the eye. A digital image processing procedure called pixel intensity equalisation is used to visualise the elemental gradient hidden in the original images. The images that result after equalisation has been carried out are printed in the lower two left hand side images of Figure 9.

In the current case the equalisation shifts the original greyscale values to higher values, and only then 
the image starts to convey the previously hidden gradient information. In the lower two left hand side images of Figure 9 low pixel brightness values (i.e. dark areas) indicate low elemental concentration and high brightness pixel values (bright areas) indicate high elemental concentration. From the bottom two left hand side images of Figure 9, it is obvious that $\mathrm{Ca}$ and $\mathrm{S}$ concentration is elevated around the black core. The gradient effect of $\mathrm{S}$ and $\mathrm{Ca}$ that can be observed after greyscale value equalisation is much more pronounced. In the bottom two left hand side images of Figure 9, the $\mathrm{Ca}$ and $\mathrm{S}$ gradient is drastically exaggerated after the equalisation process. It should be borne in mind that the concentration of $\mathrm{Ca}$ and $\mathrm{S}$ is still very low. We would estimate the $\mathrm{Ca}$ and S concentration in the black core and the red rim at about $0.4 \%$ and at $0.9 \%$ weight at the elevated area around the black core. The effect of image equalisation is that the average pixel greyscale value is increased and the greyscale values are also spread across the range from 0 to 255 . Image equalisation has also been carried out on the coloured element maps shown in Figure 8.

The total acquisition time for the $\mu$-XRF analysis was long at 36 hours. The detection limit of the instrument depends on the counting time of the X-ray detector, since longer count rates reduce the noise in the XRF spectrum, or in other words, increase the signal-to-noise ratio of an elemental peak. The longer the counting time (acquisition time) of an individual pixel spectrum, the lower the detection limit for that element. If the acquisition time was reduced to say 18 hours, the instrument software would no longer be able to detect the $\mathrm{S}$ and Ca gradient that is observable in Figure 9. The concentration of $\mathrm{S}$ and Ca, even at the elevated areas around the black core is very low, and the the instrument was just able to detect this gradient at the given, long acquisition time. If one employed shorter acquisition times the $\mathrm{S}$ and Ca gradient can not be detected with the 'Edax Eagle III' instrument. Synchrotron radiation would be the answer.

\subsection{Possible sulphate and sulphide reactions}

The most likely compound of $\mathrm{Ca}$ and $\mathrm{S}$ is calcium sulphate $\mathrm{CaSO}_{4}$ in heavy clay ceramics. Several options exist for the formation of calcium sulphate in a fired brick that is observed in Figures 8 and 9. An example of another industrial process where calcium sulphate is formed is fluidized-bed combustion of coal, where harmful sulphur released from the fired coal, is captured by limestone (i.e. calcium carbonate $\mathrm{CaCO}_{3}$ ) or sometimes dolomite $\mathrm{CaMg}\left(\mathrm{CO}_{3}\right)_{2}$, to form calcium sulphate $\mathrm{CaSO}_{4}$. There the calcium carbonate $\mathrm{CaCO}_{3}$ is converted or calcined to $\mathrm{CaO}$ at higher temperatures:

$$
\mathrm{CaCO}_{3}(s) \longrightarrow \mathrm{CaO}(s)+\mathrm{CO}_{2}(g)
$$

After the calcination process calcium oxide $\mathrm{CaO}$ then acts as a sorbent for $\mathrm{SO}_{2}$ to form $\mathrm{CaSO}_{4}$ (e.g. [34] Tullin and Ljungstrom 1989):

$$
\mathrm{CaO}(s)+\mathrm{SO}_{2}(g)+\frac{1}{2} \mathrm{O}_{2}(g) \longrightarrow \mathrm{CaSO}_{4}(s)
$$

The actual process in a fired brick may, however, not be so simple, and a variety of chemical reaction paths to form calcium sulphate have been proposed ([35] Tourneret et al. 1999):

$$
\begin{gathered}
9 \mathrm{CaCO}_{3}(s)+9 \mathrm{SO}_{2}(g) \longrightarrow 6 \mathrm{CaSO}_{4}(s)+\mathrm{CaSO}_{3}(s)+2 \mathrm{CaS}(s)+9 \mathrm{CO}_{2}(g) \\
4 \mathrm{CaSO}_{3}(s) \longrightarrow 3 \mathrm{CaSO}_{4}(s)+\mathrm{CaS}(s) \\
\mathrm{CaS}(s)+2 \mathrm{O}_{2}(\mathrm{~g}) \longrightarrow \mathrm{CaSO}_{4}(s)
\end{gathered}
$$

The latter reaction requires oxygen which is only available close to the brick surface. In the case where oxygen is in short supply, the reaction could be

$$
\mathrm{CaO}+\mathrm{SO}_{2}+3 \mathrm{CO} \longrightarrow \mathrm{CaS}+3 \mathrm{CO}_{2}
$$

The oxidation of pyrite $\mathrm{FeS}_{2}$ in the raw clay is a source of sulphur gases released during firing. The calcium carbonate reactivity is substantial at temperatures above $600^{\circ} \mathrm{C}([35]$ Tourneret et al 1999) and sulphur gases evolving during firing of pyrite play a key role. If so-called thin sections of calcareous stone are exposed to artificial $\mathrm{SO}_{2}$ gas in a lab environment, needle-like gypsum crystals form on the surface ([36] Malaga-Starzec et al. 2003). 


\subsection{Sulphate salts in the brick life cycle}

There is some evidence that brick internal salts build up during the firing process and one of the most prominent salts is calcium sulphate ([37] Brownell 1949). [38] Brownell 1960 succinctly stated that "... calcium sulphate is the most persistant sulphate in clay bodies. This is due to the higher reaction temperature required for calcium sulphate to react with silicates". The firing temperature of $1050^{\circ} \mathrm{C}$ is not sufficient for the temperature stable $\mathrm{CaSO}_{4}$ to dissociate and combine with silica. If the Ca and $\mathrm{S}$ zoning observed in Figure 8 map (c) and (l) is calcium sulphate, it is likely to be of the anhydrite variety. One could argue that this calcium sulphate anhydrite may be (re)hydrated when exposed to wheather cycling in operation to form secondary salts, e.g. hemi-hydrates $\mathrm{CaSO}_{4} \frac{1}{2} \mathrm{H}_{2} \mathrm{O}$ or hydrates, which then may cause efflorescence. Calcium sulphate solubility in water decreases with temperature (e.g. [39] Klepetsanis et al. 1999).

A strong influence of the firing atmosphere on the quantity of water soluble sulphate in bricks made from pyrite-containing clay has been reported. When clays are fired in a reducing atmosphere there is more retained sulphate compared to when the clay is fired in an oxidising atmosphere ([40] Brosnan and Sanders 2005). Efflorescence of salts and crystallisation cycles due to cyclic wetting of the brick can, under certain conditions, damage the structure ([41] Bowler and Fisher 1989; [42] Lewin 1981; [43] Larsen and Nielsen 1990; [44] Honeyborne 1998; [45] Brocken and Nijland 2004). However, the pure presence of a sulphate compound does not in itself cause damage to the ceramic structure. Cyclic water ingress or humidity or vapour must be present for damage to occur. Also, the presence of a single salt may not be damaging, whereas a cocktail of salts may ([46] Cardell 2008). With cyclic wetting, salts accumulate at the brick surface where evaporation is most rapid. The source of the salts can either be external (e.g. by mortar) or internal from the brick clay.

\section{Conclusions}

Elemental maps of the cross section of an industrially fired brick which contained a black reduction core, were generated using a commercial $\mu$-XRF desktop analyser in a 36 hour mapping process.

- From an X-ray diffraction smear sample analysis, the largest clay portion in the raw material was found to be illite. Due the fineness of this clay, gas diffusion during firing may be inhibited.

- No large scale iron gradient from $\mathrm{Fe}_{3} \mathrm{O}_{4}$ magnetite core to the $\mathrm{Fe}_{2} \mathrm{O}_{3}$ hematite outer region was detectable in the Fe $\mu$-XRF map of the brick cross section. The colour change from black core to red rim in the brick appears to arise from the oxidation state of iron.

- Elemental maps show that sulphur and calcium were not distributed evenly in the fired brick. Instead, calcium and sulphur are concentrated in a zone at the interface between black core and red rim during firing.

- No zoning of $\mathrm{Ca}$ and $\mathrm{S}$ is observed in the absence of a black reduction core - Figure 4. Red colour is not developing if the brick is fired in inert gas.

- Powder X-ray diffraction analysis on a sample taken out from the red rim of a fired brick was able to discern hematite, whilst a spinel phase was found in the black core.

- If sulphur content in a fired brick is measured quantitatively, it is important where on the cross section the sample is taken from. The sulphur content in the brick may not be uniform but may depend on the distance to the brick surface caused by $\mathrm{Ca}$ and $\mathrm{S}$ zoning in bricks with a black core.

- Even though some primary calcium sulphate $\mathrm{CaSO}_{4}$ may be present in the unfired, raw material in the form of small, white granules, a secondary type of $\mathrm{CaSO}_{4}$ appears to develop during the firing process at the interface between black core and red rim.

- It is assumed that calcium and sulphur form calcium sulphate $\mathrm{CaSO}_{4}$ via sulphur dioxide gas, which migrates from the core towards the surface of the brick during firing. 
- The concentrations of $\mathrm{Ca}$ and $\mathrm{S}$ in the fired brick sample were very low and the tabletop $\mu$-XRF instrument used was just able to detect a gradient of $\mathrm{Ca}$ and $\mathrm{S}$ on the surface of a brick cross section. Long dwell times per pixel (e.g. a dwell time of $10 \mathrm{~s}$ ) were necessary. Due to the low concentrations, resulting element gradient images had to be equalised/adjusted to visualise the gradient. Synchrotron radiation could provide better signal-to-noise ratios than the desktop instrument used in this research.

This work has contributed to the understanding of sulphate salt formation in fired clay ware. However, the elemental gradient for $\mathrm{Ca}$ and $\mathrm{S}$ reported here may be due to the particular clay composition or due to the clay mineralogy of the Gault clay used. The zoning effect around a black reduction core should be investigated with other clays and bricks. The question of what role the iron oxides $\mathrm{Fe}_{2} \mathrm{O}_{3}$ or $\mathrm{Fe}_{3} \mathrm{O}_{4}$ play in the formation of $\mathrm{CaSO}_{4}$ when a brick is fired in the presence of a black core merits further investigation.

Large sums are spent by national economies on building preservation and understanding of salt formation is vital to improve ubiquitous heavy clay building materials.

\section{Acknowledgements}

The first author was supported by SEEDA (South East England Development Agency, UK) and the University of Southampton, UK. Their assistance is acknowledged. The $\mu$-XRF analysis was carried out by Dr Ian Croudace at the National Oceanography Centre Southampton, UK. The director of the Tower Brick \& Tile Company, Selborne, UK, Patrick Benham-Crosswell, supplied clay and brick samples and supported this work in all aspects. Professor Carla Vogt and Mr Robert Lehmann, both from the University of Hannover, Institute of Anorganic Chemistry, Germany, have given valuable advice. Many thanks to Ross Williams, who performed the X-ray diffraction analysis and to Dr. T. Allan and M. Dicken, for proofreading the manuscript.

\section{References}

[1] M. García-Heras and J. Ma Rincón. Microstructural and microanalytical study (SEM/EDX) of Celtiberian potsherds from the spanish central meseta. Geoarchaeology, 11(4):329-344, 1996.

[2] S. Pavia. The determination of brick provenance and technology using analytical techniques from the physical sciences. Archaeometry, 48(2):201-218, May 2006.

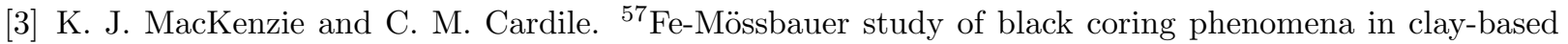
ceramic materials. Journal of Materials Science, 25:2937-2942, 1990.

[4] W. E. Brownell. Black coring in structural clay products. Journal of the American Ceramic Society, 40(6):179-187, 1957.

[5] A. Barba, F. Negre, M. Ortis, and A. Escardino. Oxidation of black core during the firing of ceramic ware - 3. influence of the thickness of the piece and the composition of the black core. British Ceramic Transactions, 91:36-46, 1992.

[6] D. Brosnan and J. Sanders. An introduction to black coring - an old manufacturing problem gets new attention. Brickyard Road, 10 (October):22-23, 2003.

[7] M. Sveda. Review paper - the effect of black coring on the properties of clay bricks. Tile and Brick International - Manual, pages 30-36, 2006.

[8] J. Otto. Black cores in ceramic products (in german). Keramische Zeitschrift, 31(2):77-78, 1979.

[9] R. Toledo, D. R. Dos-Santos, R. T. Faria, J. G. Carrio, L. T. Auler, and H. Vargas. Gas release during clay firing and evolution of ceramic properties. Applied Clay Science, 27:151-157, 2004. 
[10] P. Fischer, B. Epstein, and R. Proff. Directional effects in extruded clay ceramics. Berichte der Deutschen Keramischen Gesellschaft, 63(7/8):352-357, 1986.

[11] M. Sveda and S. Uncik. The effect of the pore structure of a brick body on reduction core formation in roofing tiles. Tile and Brick International - Manual, pages 30-35, 2008.

[12] X. Elias. The formation and consequences of black core in ceramic ware. Interceram, 29(3):380-384, 1980.

[13] D. A. Brosnan. Plain talk on black coring and clay bricks. Technical report, Clemson University, South Carolina, 29625 USA, February 2009.

[14] B. Butterworth and D. B. Honeyborne. Bricks and clays of the Hastings beds. Transactions of the British Ceramic Society, 51:211-259, 1952.

[15] R. E. Arnold and G. H. Duncombe. Clay sewerpipe manufacture VII. Low temperature oxidation. Journal of the American Ceramic Society, 12(6):423-429, 1929.

[16] N. G. Holmstrom. Fast firing of triaxial porcelain. Bulletin of the American Ceramic Society, 60(4):470473, 1981.

[17] James E. Funk. Designing the optimum firing curve for porcelains. Ceramic Bulletin, 61(6):632-635, 1982.

[18] C. Agrafiotis. Energy saving technologies in the European ceramic sector: a systematic review. Applied Thermal Engineering, 21(12):1231-1249, August 2001.

[19] A. A. Jackson and P. Stone. Bedrock geology UK South - an explanation of the bedrock geology map of England and Wales - with geological map 1:625000, 2008.

[20] M. F. Gazulla, M. P. Gomez, M. Orduna, and M. Rodrigo. New methodology for sulfur analysis in geological samples by WD-XRF spectrometry. X-Ray Spectrometry, 38:3-8, 2009.

[21] G. Bitossi, R. Giorgi, M. Mauro, B. Salvadori, and L. Dei. Spectroscopic techniques in cultural heritage conservation: A survey. Applied Spectroscopy Reviews, 40(3):187-228, 2005.

[22] M. Manso and M. L. Carvalho. Application of spectroscopic techniques for the study of paper documents: A survey. Spectrochimica Acta Part B: Atomic Spectroscopy, 64(6):482-490, June 2009.

[23] J.M. Davis, D.E. Newbury, P. Rangaraju, S. Soundrapanian, and C. Giebson. Milli x-ray fluorescence x-ray spectrum imaging for measuring potassium ion intrusion into concrete samples. Cement and Concrete Composites, 31(3):171-175, March 2009.

[24] D. M. Moore and R. C. Reynolds. X-Ray Diffraction and the Identification and Analysis of Clay Minerals (2nd ed.). Oxford University Press, 1997.

[25] S.J. Chipera and D.L. Bish. Fullpat: A full-pattern quantitative analysis program for x-ray powder diffraction using measured and calculated patterns. Journal of Applied Crystallography, 35:744-749, 2002.

[26] P. E. Biscaye. Mineralogy and Sedimentation of Recent Deep-Sea Clay in the Atlantic Ocean and Adjacent Seas and Oceans. Geological Society of America Bulletin, 76(7):803-832, July 1965.

[27] H. J. Lucas-Tooth and C. Pyne. The accurate determination of major constituents by x-ray fluorescence analysis in the presence of large interelement effects. Advances in X-ray Analysis, 7:523-541, 1964.

[28] H. J. Lucas-Tooth and B. J. Price. A mathematical method for investigation of inter-element effects in x-ray fluorescent analysis. Metallurgia, 64(383):149-161, 1961. 
[29] R. Tertian and F. Claisse. Principles of Quantitative X-Ray Fluorescence Analysis. Heyden and Son Ltd, London, 1982.

[30] I.L. Freeman. Mineralogy of 10 british brick clays. Clay Minerals Bulletin, 5:474-486, 1964.

[31] F. Gonzalezgarcia, V. Romeroacosta, G. Garciaramos, and M. Gonzalezrodriguez. Firing transformations of mixtures of clays containing illite, kaolinite and calcium carbonate used by ornamental tile industries. Applied Clay Science, 5(4):361-375, December 1990.

[32] M. Jordán. Firing transformations of cretaceous clays used in the manufacturing of ceramic tiles. Applied Clay Science, 14(4):225-234, April 1999.

[33] M. Fernández, A. Lyngfelt, and B. Steenari. Reaction between limestone and $\mathrm{SO}_{2}$ under conditions alternating between oxidizing and reducing. The effect of short cycle times. Energy \& Fuels, 14(3):654662, May 2000.

[34] C. Tullin and E. Ljungstroem. Reaction between calcium carbonate and sulfur dioxide. Energy $\mathcal{G}$ Fuels, 3(3):284-287, May 1989.

[35] L. Tourneret, F. Berger, C. Mavon, and A. Chambaudet. Efflorescence - study of the formation of calcium sulphate during firing of ceramic ware. Ziegelindustrie International, 6:15-25, 1999.

[36] K. Malaga-Starzec. Efflorescence on thin sections of calcareous stones. Journal of Cultural Heritage, 4(4):313-318, December 2003.

[37] W. E. Brownell. Fundamental factors influencing efflorescence of clay products. Journal of the American Ceramic Society, 32(12):375-389, 1949.

[38] W. E. Brownell. Retention of sulfates by fired clay products. Journal of the American Ceramic Society, 43(4):179-183, 1960.

[39] P. Klepetsanis, E. Dalas, and P. Koutsoukos. Role of temperature in the spontaneous precipitation of calcium sulfate dihydrate. Langmuir, 15(4):1534-1540, February 1999.

[40] D. Brosnan and J. Sanders. Residual sulfur in clay bricks - investigations on North American products. Ziegelindustrie International, 2005(10):25-31, 2005.

[41] G. K. Bowler and K. Fisher. Soluble salt analysis and indexation of sulphation risk. Masonry International - Journal of the British Masonry Society, 3(2):62-67, 1989.

[42] S. Z. Lewin. The mechanism of masonry decay through crystallization, pages 120-144. The National Academies Press, 1981.

[43] E. Larsen and C. Nielsen. Decay of bricks due to salt. Materials and Structures, 23(1):16-25, January 1990.

[44] David Honeyborne. Weathering and decay of masonry, chapter 7, pages 153-177. ButterworthHeinemann, first edition, 1998.

[45] H. Brocken and T. Nijland. White efflorescence on brick masonry and concrete masonry blocks with special emphasis on sulfate efflorescence on concrete blocks. Construction and Building Materials, 18:315-323, 2004.

[46] C. Cardell, D. Benavente, and J. Rodriguez-Gordillo. Weathering of limestone building material by mixed sulfate solutions. Characterization of stone microstructure, reaction products and decay forms. Materials Characterization, 59(10):1371-1385, October 2008. 